Check for updates

Cite this: J. Mater. Chem. A, 2022, 10 , 2362

Received 21st June 2021

Accepted 2nd September 2021

DOI: $10.1039 / \mathrm{d} 1 \mathrm{ta0} 240 \mathrm{c}$

rsc.li/materials-a

\section{Fabrication of multi-layered structures for proton conducting ceramic cells}

\author{
Wendelin Deibert, ${ }^{* a}$ Mariya E. Ivanova, (D) *a Yuanye Huang, ${ }^{\mathrm{b}}$ Rotraut Merkle, (D) ${ }^{\mathrm{b}}$ \\ Joachim Maier ${ }^{\mathrm{b}}$ and Wilhelm A. Meulenberg (D) ac
}

Protonic ceramic fuel cells offer a high potential to produce electrical energy in a very efficient way. The performance of such a device among others is highly dependent on the electrolyte material and its thickness. Therefore, multilayer structures are used to reduce the electrolyte thickness down to 10-20 $\mu \mathrm{m}$, supported by a much thicker porous anode. In this work sequential tape-casting is used to fabricate half-cells consisting of a BZCY electrolyte and a BZCY/NiO support which also serves as the anode layer. The starting powders are characterised as well as the thermal behaviour of the half-cells during heat treatment. Sintering experiments show that a temperature of $T \geq 1450{ }^{\circ} \mathrm{C}$ is needed to achieve the desired microstructure. After that a scale-up approach to a size of the half-cells of about $25 \mathrm{~cm}^{2}$ is shown. The influence of the processing temperature on the microstructure is shown by detailed XRD and SEM studies. The formation of a $\mathrm{BaY}_{2} \mathrm{NiO}_{5}$ transient liquid phase during the heat treatment of the cells is clearly demonstrated. Finally, the proton conductivity of the tape-cast cells shows competitive values of $\sigma=0.003 \mathrm{~S} \mathrm{~cm}^{-1}$ at $600{ }^{\circ} \mathrm{C}$ with the advantage of an industrially proven and up-scalable manufacturing technique.

\section{Introduction}

Protonic ceramic cells (PCCs) typically use acceptor-doped $\mathrm{Ba}(\mathrm{Zr}, \mathrm{Ce}) \mathrm{O}_{3}$ as electrolytes, which allow for reducing the operation temperature to $400-600{ }^{\circ} \mathrm{C}$ owing to an increased ion conductivity at intermediate temperatures. ${ }^{1,2}$ In fuel cell mode (PCFC) these cells have the advantage of water formation at the cathode, hence no fuel dilution occurs and this leads to high fuel utilization and increased efficiency. ${ }^{3}$ Potential applications for PCCs can be found in either mobile or stationary fields, e.g. heating and power systems for houses, electric vehicles such as buses, or special cases as power supply for mobile electronic devices, ${ }^{4}$ or for $\mathrm{H}_{2}$ generation. ${ }^{5}$ Interestingly, with adjusted catalytic activity at the anode side, a wide range of fuels such as ammonia and different hydrocarbons and alcohols can be used instead of hydrogen. ${ }^{6}$ In recent years, PCFC performance has been impressively increased to more than $1.2 \mathrm{~W} \mathrm{~cm}^{-2}$ at $600{ }^{\circ} \mathrm{C}$ by improving the processing of the electrolyte layer, choice of cathode materials, interface contacts through development of interlayers. $^{7-10}$ ${ }^{a}$ Forschungszentrum Jülich GmbH, Institute of Energy and Climate Research, Materials
Synthesis and Processing (IEK-1), D-52425 Jülich, Germany. E-mail: w.deibert@
fz-juelich.de; m.ivanova@fz-juelich.de
${ }^{b}$ Max Planck Institute for Solid State Research, Heisenbergstr. 1, 70569 Stuttgart,
Germany
${ }^{c}$ University of Twente, Faculty of Science and Technology, Inorganic Membranes, P.O. Box 217, 7500 AE Enschede, The Netherlands
This work reports the sequential tape-casting employed as a processing technology to develop large area protonic ceramic half-cells from a ceramic powder, specially designed via the solid state reactive sintering (SSRS), used for the electrolyte layer and a cermet composite powder for the anode layer. Two key results are shown: (i) the combination of tape casting and reactive sintering is able to produce large-area anode/electrolyte membrane assemblies for a comparably low Ce content of 20 mol\%. Accounting the strong dependence of sintering behaviour, grain size and grain boundary electrical characteristics on Ce content, this is not trivial. (ii) The achieved total proton conductivity of the electrolyte is suitable for PCFCs, although was somewhat lower than that measured for respective bulk samples. The solid-state reactive sintering with $\mathrm{NiO}$ as a sintering aid was reported to lead to an improved electrolyte processing due to the formation of a transient liquid phase. ${ }^{11,12}$ However, anode-supported cells reported in these works were typically fabricated using uniaxial pressing or PLD depositiontechnique for the electrolyte formation, which as processing routes are not really suitable for large-area ceramic cell manufacturing. ${ }^{10,13-15}$ This means that the manufacturing of these cells is limited to small areas which cannot be scaled-up easily, or are limited to a certain thickness, which specifically is the case of uniaxial pressing.

Tape-casting is an industrially proven manufacturing method for large area ceramic sheets. This method was employed to fabricate supporting anode layer $\mathrm{NiO}-\mathrm{BaZr}_{0.1^{-}}$ $\mathrm{Ce}_{0.8} \mathrm{Y}_{0.1} \mathrm{O}_{3}$ (BZCY), as reported in ref. 16, while the electrolyte 
layer was then applied either by screen printing on the presintered substrate or on a raw substrate tape, ${ }^{\mathbf{1 7}}$ or by suspension spraying. ${ }^{18}$ Applying different fabrication techniques for one component usually leads to increased complexity of the process and increased cost, which is detrimental for the potential commercial application in the future.

Tape-casting of asymmetric anode/electrolyte $\mathrm{BaZr}_{0.8} \mathrm{Y}_{0.2} \mathrm{O}_{3}$ (BZY) structures using SSRS for the electrolyte layer is reported in ref. 19. However, in this work very high $\mathrm{NiO}$ additions of $4 \mathrm{wt} \%$ had to be used to achieve full densification, and the sample diameter was only $2 \mathrm{~cm}$. In ref. 20 a very high Ce content of $70 \mathrm{~mol} \%$ was used (critical with respect to long-term stability, see below) many tape-cast layers were then laminated (unpractical for upscaling), and the cell size was only $3.3 \mathrm{~cm}^{2}$, which limits the applicability of such an approach. In ref. $5 \mathrm{SrZr}_{0.5^{-}}$ $\mathrm{Ce}_{0.4} \mathrm{Y}_{0.1} \mathrm{O}_{3-\delta}$ is used in the anode substrate, which promotes the densification of the BZCY electrolyte layer by its high sintering shrinkage. However, one has to keep in mind that adding another material into the anode-electrolyte assembly increases the complexity of the system (e.g. by an increased thermal expansion coefficient of strontium cerates $\left.{ }^{21}\right)$.

The cation composition is decisive for the performance of the components. Several groups have investigated partial Ce substitution in BZY, because increasing the Ce content facilitates the sintering and also leads to higher proton retention at elevated temperatures. However, while $\mathrm{BaZrO}_{3}$ is thermodynamically stable against decomposition to $\mathrm{BaCO}_{3}, \mathrm{Ba}(\mathrm{OH})_{2}$, $(\mathrm{Zr}, \mathrm{Y}) \mathrm{O}_{2-\delta}$ in $\mathrm{H}_{2} \mathrm{O}$ and $\mathrm{CO}_{2}$-containing atmospheres, $\mathrm{BaCeO}_{3}$ is less chamically stable (see e.g. discussion in ref. 1 and 2). In the present study the ceria content was limited to $20 \mathrm{~mol} \%$ to ensure stability of the electrolyte layer against hydroxide or carbonate formation, ${ }^{\mathbf{1 , 2 2}}$ in contrast to much higher ceria contents used e.g. in ref. 16 and 17. Since a compromise between processability, stability, and resulting conductivity needs to be achieved, we find it important to explore the selected combination of manufacturing routes (SSRS, tape casting and co-firing) also for the processing of a material with a relatively low Ce content of $20 \mathrm{~mol} \%$ compared to what reported previously. A concentration of Y acceptor dopant fixed to 17.5 mol\% was chosen for both the anode and the electrolyte layers, while the amount of $\mathrm{NiO}$ additive, used to enhance the sintering of the electrolyte layer, was $0.5 \mathrm{wt} \%$.

\section{Experimental}

Y-doped $\mathrm{Ba}(\mathrm{Zr}, \mathrm{Ce}) \mathrm{O}_{3}(\mathrm{BZCY})$ perovskite powders with a nominal composition $\mathrm{Ba}_{1.015} \mathrm{Zr}_{0.625} \mathrm{Ce}_{0.2} \mathrm{Y}_{0.175} \mathrm{O}_{3-\delta}$ (BZCY) used in the tape-casting processing were synthesized from stoichiometric mixtures of $\mathrm{BaCO}_{3}, \mathrm{ZrO}_{2}, \mathrm{CeO}_{2}$ and $\mathrm{Y}_{2} \mathrm{O}_{3}$. The solid-state reactive sintering process $(\mathrm{SSRS})^{12}$ yields enhanced sintering behaviour, in which the intimately mixed and ground precursors are used to form the final functional material. In the present study, a combination of the SSRS and pre-calcination was applied for the electrolyte layer to decrease the otherwise huge volume shrinkage typical for the SSRS process. The powder for the electrolyte layer with $20 \mathrm{~mol} \% \mathrm{Ce}$ and $17.5 \mathrm{~mol} \%$ Y (BZCY-EL) was prepared by $1 \mathrm{~h}$ dry ball milling (vibration zirconia ball mill with one $5 \mathrm{~cm}$ diameter zirconia ball, Friatec) of the precursor mixture $\mathrm{BaCO}_{3}$ (Alfa Aesar), $\mathrm{ZrO}_{2}$ (Tosoh TZ0), $\mathrm{CeO}_{2}$ (Sigma Aldrich), and $\mathrm{Y}_{2} \mathrm{O}_{3}$ (Alfa Aesar), calcination for $1 \mathrm{~h}$ at $1100{ }^{\circ} \mathrm{C}$ in air (heating/cooling rate $300 \mathrm{~K} \mathrm{~min}^{-1}$ ), and then wet milling of this powder together with $0.5 \mathrm{wt} \% \mathrm{NiO}$ (Alfa Aesar, 325 mesh) for $24 \mathrm{~h}$ (in i-propanol, zirconia jar and balls, Fritsch Pulverisette 5). The BZCY perovskite for the substrate layer with $20 \mathrm{~mol} \% \mathrm{Ce}$ and $17.5 \mathrm{~mol} \% \mathrm{Y}$ (BZCY-SU) was prepared by solid state reaction from $\mathrm{BaCO}_{3}$ (Alfa Aesar), $\mathrm{Zr}_{0.83} \mathrm{Y}_{0.17} \mathrm{O}_{1.915}$ (Tosoh TZ10), $\mathrm{CeO}_{2}$ (Sigma Aldrich), and $\mathrm{Y}_{2} \mathrm{O}_{3}$ (Alfa Aesar) by $1 \mathrm{~h}$ dry ball milling, calcination for $8 \mathrm{~h}$ at $1200^{\circ} \mathrm{C}$ in air, followed by twice repeated dry ball milling and calcination at $1300{ }^{\circ} \mathrm{C}$. For both powders a nominal Ba excess of $1.5 \mathrm{~mol} \%$ was added to compensate possible Ba evaporation during the thermal treatments (a larger excess of 3\% decreases the mechanical stability of sintered pellets).

The chemical composition of the powders was determined by ICP-OES using an iCAP 7600 measurement device from Thermo Fisher Scientific.

For the tape-casting a suspension consisting of the ceramic powder with several (organic) additives and solvent was prepared and spread over a polymeric foil. For the slurry preparation, as a solvent ethanol and methyl-ethyl-ketone mixture in $1: 2$ ratio was used. The binder system consisted of PVB-98 as the binder and Solusolv S2075 combined with PEG 400 as plasticisers. A dispersing agent Nuosperse FX 9086 was added to better separate the single powder particles in the slurry. For the substrate layers a cermet consisting of NiO and BZCY was prepared by mixing the two powders in a weight ratio of $60: 40$. For sintering experiments, single electrolyte and substrate layers as well as electrolyte-substrate bi-layers were fabricated by tape-casting. The tape thickness was controlled by means of different parameters, especially the blade gap between the polymer foil and the so-called doctor blade. The tape-casting experiments were performed using a micro tape-casting machine "KAROcast 300-7" by KMS Automation GmbH, Dresden Germany. More details about the used equipment and the slurry preparation can be found in ref. 23.

Aiming to increase the supporting layer thickness, the green electrolyte-substrate tape assembly was laminated with a single substrate tape using a warm press by $\mathrm{P} / \mathrm{O}$ Weber. Lamination of tape layers was performed by applying pressure at $80{ }^{\circ} \mathrm{C}$ until sufficient connection between the individual layers was obtained. Cross sections of the co-fired laminated structures were microscopically controlled to ensure good lamination quality with sufficient adherence of the layers.

For estimation of the green tape's shrinkage an optical dilatometer “TOMMI plus” by Fraunhofer ISC Würzburg, Germany was used. The instrument consists of a furnace with quartz glass windows, a light source and a camera. Images of the sample silhouette were continuously recorded during the heat treatment. By means of smart selection of the sample geometry, the shrinkage was determined. More details can also be found in ref. 23 .

The thermal expansion of the electrolyte and the substrate material was evaluated by means of dilatometry performed with 
a NETZSCH DIL 402C dilatometer on a fully sintered specimens with a heating rate of $5 \mathrm{~K} \mathrm{~min}^{-1}$ in air.

Thermogravimetry was carried out in air to characterize the burn out behaviour of organic additives from green tapes. For this purpose NETZSCH STA 449F3 instrument was used.

The sintering of green tapes was performed in a muffle furnace in static air. Samples were placed on a $\mathrm{MgO}$ base plate (anode layer downwards) without a cover. For comparison, some small sample pieces were also sintered under a $\mathrm{MgO}$ cover, or under a $\mathrm{MgO}$ cover with some $\mathrm{BaZrO}_{3} / \mathrm{BaCO}_{3}$ sacrificial powder placed nearby, to decrease potential $\mathrm{BaO}$ losses by evaporation.

Small pieces of the supported solid electrolyte assemblies (typically $5 \times 5 \mathrm{~mm}^{2}$ ) were used for the electrical impedance measurements (Novocontrol Alpha A, AC amplitude $0.02 \mathrm{~V}$, frequency $10^{6}-0.1 \mathrm{~Hz}$ ). The samples were coated on both sides with Ag paste (Leitsilber) and contacted with Pt mesh current collectors in pseudo-four-point mode to cancel the Pt wire resistances. The conductivity was measured in heating as well as cooling in humid $3 \% \mathrm{H}_{2}$ in $\mathrm{Ar}$ (20 mbar water). Owing to the open porosity in the reduced anode layer and the low thickness (ca. $10 \mu \mathrm{m}$ ) of the dense electrolyte layer, the equilibration of the hydration reaction was fast.

\section{Results and discussion}

\subsection{Powder characterization and composition}

The starting powder plays a key role in ceramic processing and strongly influences the manufacturing and sintering properties. A target composition of $\mathrm{Ba}_{1.015} \mathrm{Zr}_{0.625} \mathrm{Ce}_{0.2} \mathrm{Y}_{0.175} \mathrm{O}_{3-\delta}$ was chosen for both layers. For the electrolyte layer, SSRS of BZCY with addition of a small amount of NiO is applied.11,12 The original SSRS method directly sinters the ball-milled $\mathrm{BaCO}_{3}-\mathrm{ZrO}_{2}-$ $\mathrm{CeO}_{2}-\mathrm{Y}_{2} \mathrm{O}_{3}-\mathrm{NiO}$ powder mixture. We have modified it by first calcining the powder mixture at $1100{ }^{\circ} \mathrm{C}$, which leads to a partial decomposition of the $\mathrm{BaCO}_{3}$ (XRD in Fig. 1) before wet milling in order to decrease the volume reduction in the sintering step. This treatment still leaves a comparably high specific surface area of $3.7 \mathrm{~m}^{2} \mathrm{~g}^{-1}$ to have a sufficient driving force for the

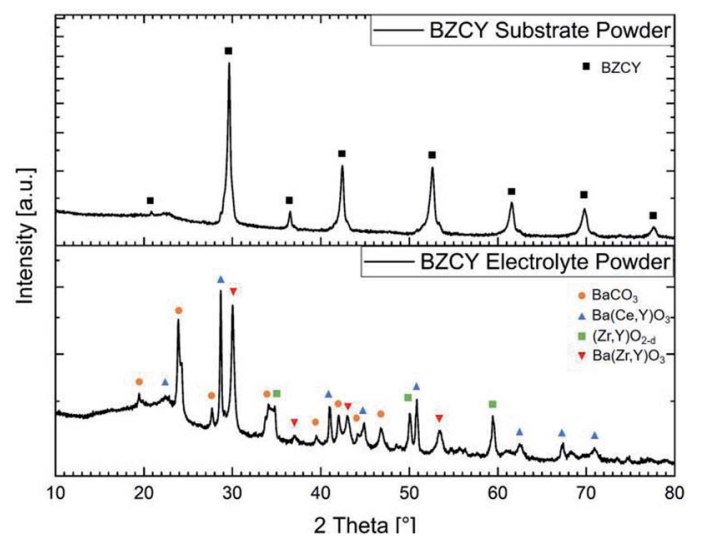

Fig. 1 X-ray diffractograms of the BZCY substrate and electrolyte powders as prepared at $1300^{\circ} \mathrm{C}$ and $1100{ }^{\circ} \mathrm{C}$, respectively.
Table 1 Particle size and specific surface area of the ceramic powders used in the present work

\begin{tabular}{lllll}
\hline Notation & Remark & $\begin{array}{l}\text { Calcination } \\
\text { temperature }\left[{ }^{\circ} \mathrm{C}\right]\end{array}$ & $D_{50}[\mu \mathrm{m}]$ & $A_{\text {spec }}\left[\mathrm{m}^{2} \mathrm{~g}^{-1}\right]$ \\
\hline BZCY-EL & Calcined & 1100 & 0.6 & 3.7 \\
BZCY-SU & Calcined & 1300 & 0.7 & 1.9 \\
NiO & - & - & 0.7 & 2.4
\end{tabular}

densification during the sintering process. The particle size and specific surface areas for all powders used in this work are summarised in Table 1 . In this initial calcination step two perovskite phases are formed, a Ce-rich composition with larger lattice parameter, and a Zr-rich composition, as shown in Fig. 1.

For the anode support layer, the final microstructure is intended to be porous (with most of the porosity arising from the reduction of $\mathrm{NiO}$ to $\mathrm{Ni}$ ) and a preferable pore size in the micrometre range. Thus, for the anode layer, the perovskite structure of the BZCY was largely formed before the sintering step, by classical solid-state reaction with repeated calcination at $1300{ }^{\circ} \mathrm{C}$ and dry ball milling (Fig. 1). This procedure yields a specific surface area of $1.9 \mathrm{~m}^{2} \mathrm{~g}^{-1}$. The properties of the commercially available NiO (Vogler) fit very well to the BZCY-SU powder without any additional treatment (Table 1).

In the present study we use a Y concentration of $17.5 \mathrm{~mol} \%$ for the anode, as well as for the electrolyte layer. In principle, apart from the small region in vicinity to the electrolyte, which is electrochemically active for hydrogen oxidation, most of the anode layer would not require proton conductivity. The use of $\mathrm{Ba}(\mathrm{Zr}, \mathrm{Ce}) \mathrm{O}_{3}$ without acceptor dopant for the support layer on which thin Y-doped anode functional layer is formed, may be considered promising because it would diminish volume changes of the whole cell caused by hydration/dehydration. However, preliminary experiments showed that in order to form the transient liquid phase which facilitates the sintering process, certain amount of acceptor dopant is required in the pre-formed $\mathrm{Ba}(\mathrm{Zr}, \mathrm{Ce}) \mathrm{O}_{3}$ perovskite used to manufacture the anode support layer. NiO plays also a very important role as a sintering additive in the electrolyte layer. It was found that higher concentrations of $\mathrm{NiO}$ up to $1 \mathrm{wt} \%$ are beneficial for the sintering properties and the grain growth but have a negative effect on the protonation and conductivity of the material, see e.g. ${ }^{24-27}$ Therefore, a comparably low NiO concentration of $0.5 \mathrm{wt} \%$ (corresponding to about $2 \mathrm{~mol} \%$ relative to the sum of B-site cations) was chosen for the present work, which suffices for efficient sintering.

Table 2 Chemical composition (site occupancy) of the starting powders determined by ICP-OES

\begin{tabular}{llllll}
\hline Powder & $\mathrm{Ba}$ & $\mathrm{Zr}$ & $\mathrm{Ce}$ & $\mathrm{Y}$ & $\mathrm{Ni}$ \\
\hline BZCY-EL $^{a}$ & 1.053 & 0.61 & 0.212 & 0.178 & 0.022 \\
BZCY-SU $^{a}$ & 1.03 & 0.612 & 0.211 & 0.178 & -
\end{tabular}

${ }^{a}$ Values are corrected by assuming $1 \% \mathrm{HfO}_{2}$ in $\mathrm{ZrO}_{2}$ and normalised by the sum of B-cations. 


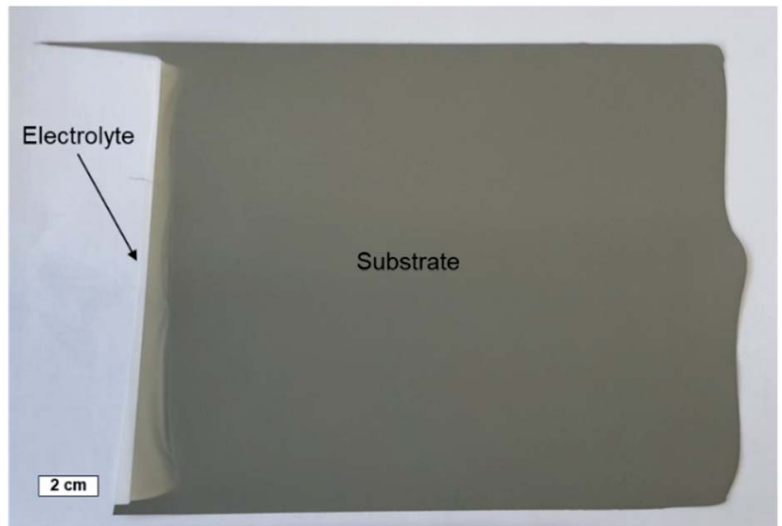

Fig. 2 Sequentially cast green tapes, consisting of a thin BZCY-solid electrolyte layer (bottom) and a thick NiO/BZCY-substrate layer (top).

In literature there are reports on BZCY electrolyte layers which were screen-printed or drop-cast on NiO/BZCY substrates without deliberate $\mathrm{NiO}$ addition into the electrolyte layer. However, it is expected that during sintering some NiO from the support will diffuse into the electrolyte layer and activate the SSRS process there..$^{7,9,25,28}$ In order to have well-defined initial conditions, we prefer to add a controlled amount of NiO directly into the powder used for the electrolyte layer processing. Then it is available for the formation of a transient liquid phase ${ }^{11,12,24}$ together with $\mathrm{BaCO}_{3}, \mathrm{ZrO}_{2}, \mathrm{CeO}_{2}, \mathrm{Y}_{2} \mathrm{O}_{3}$, which are still unreacted in the early stage of sintering.

An ICP-OES analysis was performed to verify the actual compositions of both perovskite BZCY-SU and BZCY-EL powders. The result is listed in Table 2 .

Small deviations from the nominal composition can be attributed to weighting errors and also to the fact that $\mathrm{ZrO}_{2}$ always contains small amounts of $\mathrm{HfO}_{2}$, which is not attributed to $\mathrm{Zr}$ in the ICP-OES measurement.

\subsection{Tape casting}

Single electrolyte and substrate layers, as well as electrolytesupport bi-layer assemblies were prepared by tape-casting.

Important casting parameters are listed in Table 3. For the single electrolyte layers, a higher blade gap was used compared to that used for casting the electrolyte layers in the bi-layer assemblies. This was necessary to ensure sufficient mechanical stability of the single layers in order to be subjected to further tests (further experiments are not manageable with 30 $\mu \mathrm{m}$ thin single layers).

The electrolyte-substrate assemblies were fabricated by means of casting sequentially the electrolyte and after drying for $6 \mathrm{~h}$,

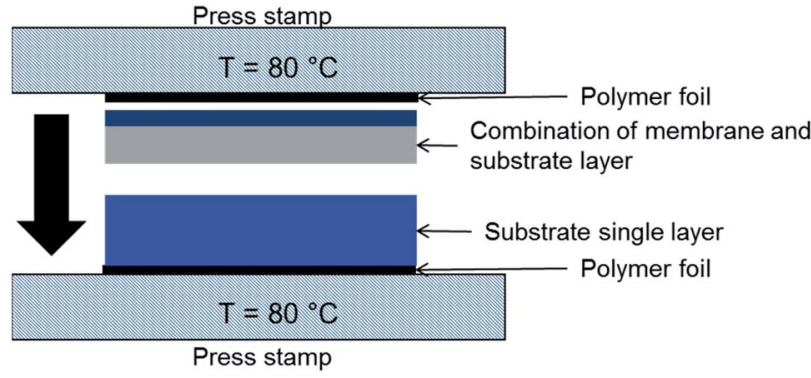

Fig. 3 Schematic illustration of the tool used for lamination of green tapes, as shown here $\mathrm{NiO} / \mathrm{BZCY}-\mathrm{SU}$ substrate layer (bottom) and $\mathrm{NiO} /$ BZCY-BZCY-EL assembly layer (top).

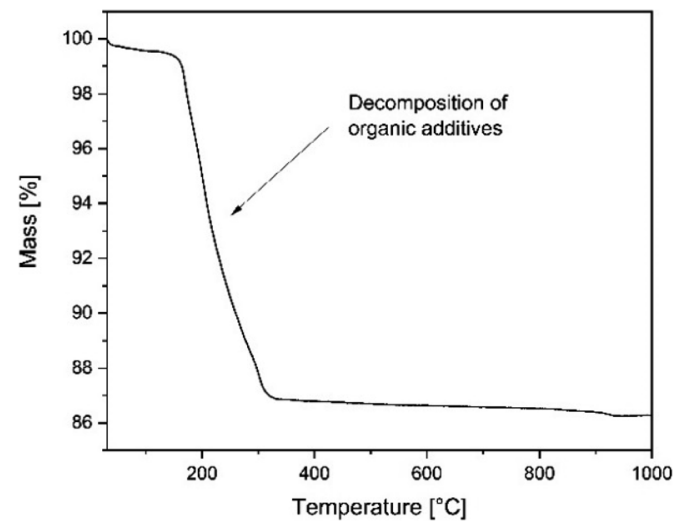

Fig. 4 Thermogravimetric measurement of $\mathrm{NiO} / \mathrm{BZCY}$ green tapes in air, heating rate of $5 \mathrm{~K} \mathrm{~min}^{-1}$.

casting the substrate layer on top. After the complete tape dried, a uniform and defect free tape was obtained as shown in Fig. 2.

\subsection{Lamination}

Lamination technique was used to increase the substrate thicknesses. A schematic of the process is depicted in Fig. 3. The tapes were laminated at $80{ }^{\circ} \mathrm{C}$ with 8-12 MPa pressure applied for $60 \mathrm{~s}$. Substrate assemblies with good adhesion of the layers and no delamination after sintering were obtained with $9 \mathrm{MPa}$ lamination pressure. The microstructure in the connection zone of the substrate layers is not influenced significantly as shown in Section 3.5.2.

\subsection{Thermal treatment}

3.4.1. Burn-out of the organic additives. Usually, the green tapes, fabricated by means of the tape-casting technique,

Table 3 Key processing parameters for the fabrication of BZCY layers

\begin{tabular}{|c|c|c|c|}
\hline Notation & $\begin{array}{l}\text { Casting speed } \\
{\left[\mathrm{mm} \mathrm{s}^{-1}\right]}\end{array}$ & $\begin{array}{l}\text { Blade gap } \\
{[\mu \mathrm{m}]}\end{array}$ & $\begin{array}{l}\text { Green thickness } \\
{[\mu \mathrm{m}]}\end{array}$ \\
\hline BZCY-electrolyte single layer & 5 & 300 & 110 \\
\hline BZCY-electrolyte in bi-layer & 5 & 80 & 30 \\
\hline BZCY/NiO-substrate layer & 2.5 & 800 & 300 \\
\hline
\end{tabular}




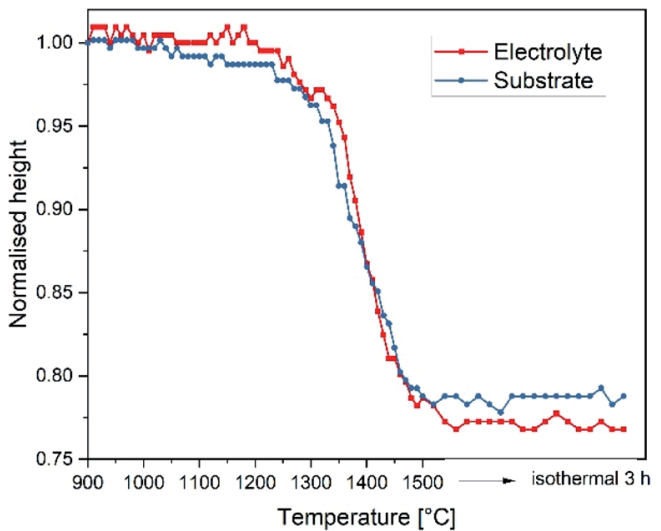

Fig. 5 Shrinkage of electrolyte and substrate single tapes determined by optical dilatometry, heating rate of $2 \mathrm{~K} \mathrm{~min}^{-1}$.

contain large amount of organic additives. During the sintering procedure, these organics are released from the tapes. ${ }^{29}$ If the calcination process happens too fast, defects such as cracks and holes can easily occur in the layer. Therefore, a good knowledge about the burn-out behaviour of the layers is advantageous. In Fig. 4 thermogravimetrically detected mass change of a sequentially tape-cast two-layer NiO-BZCY-SU/BZCY-EL assembly is shown. Starting at about $200{ }^{\circ} \mathrm{C}$, a large mass decrease of around $12 \%$ was detected, which is caused by the decomposition of the binder and the other additives. This process is accomplished at around $350{ }^{\circ} \mathrm{C}$. Therefore, in the real cell processing, it is necessary to apply low heating rate, e.g. $0.5 \mathrm{~K} \mathrm{~min}^{-1}$ to ensure sufficiently slow release of all organic constituents of the tapes and also to help defect free layers formation. To achieve complete release of the organic components, specifically in large samples, the thermal treatment was performed up to $900{ }^{\circ} \mathrm{C}$ (see also Fig. 8a).

3.4.2. Sintering studies on single layers. Sintering of the tape-cast layers is an important step in the manufacturing of flat ceramic components. The lateral shrinkage of the layers can be measured with an optical dilatometry. For this, particular sample preparation is required. Stripes with a width of $1.5 \mathrm{~cm}$

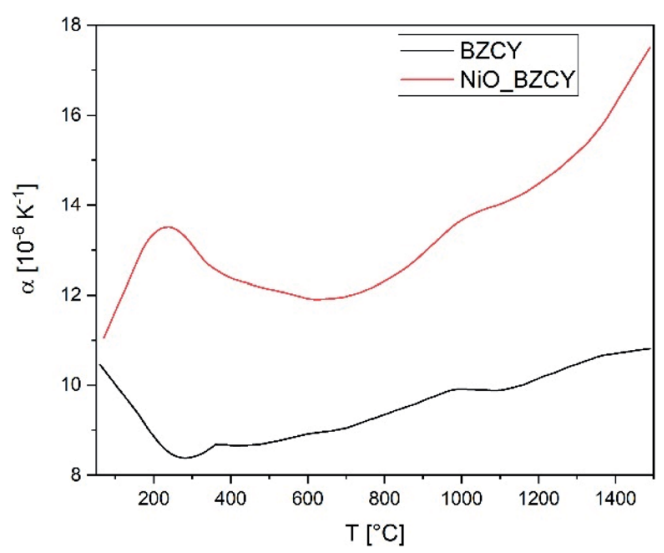

Fig. 6 Coefficient of thermal expansion $\alpha$ of BZCY-EL and NiO/BZCY$\mathrm{SU}$ in the temperature range from room temperature to $1500^{\circ} \mathrm{C}$. and a length of $5 \mathrm{~cm}$ were cut out of the tapes and rolled to form cylindrically shaped samples, which were heated in the optical dilatometer after the organic release was carried out in another oven. $^{23,30}$ During the heat treatment, the silhouette of the cylinder was captured by a camera. The reduction of the cylinder height corresponds directly to the lateral shrinkage of the tape. In Fig. 5 the height of BZCY-EL and NiO/BZCY-SU samples is plotted versus the temperature and the holding time. Both layers show similar sintering behaviour, which is beneficial for their co-sintering from the perspective of PCFC half cells manufacturing. It is furthermore visible that both layers become fully densified after $3 \mathrm{~h}$ at $1500{ }^{\circ} \mathrm{C}$. These results are very helpful to select a suitable temperature program for the sintering of bi-layer ceramic assemblies. To obtain a fully densified electrolyte layer on a composite porous support, sintering temperature of $1500{ }^{\circ} \mathrm{C}$ or slightly lower was sufficiently. Although sintering at higher temperatures might be beneficial, especially regarding to the grain growth and the reduction of the grain boundary resistance of the electrolyte layer, it increases the risk of $\mathrm{Ba}$ evaporation and associated functional disadvantages.

3.4.3. Thermal expansion. Coefficient of thermal expansion (CTE) of the electrolyte and the support material, respectively BZCY-EL and NiO/BZCY-SU, was determined using dense sintered specimens as described in the experimental part. Fig. 6 depicts the result. The peak in CTE for NiO/BZCY-SU between 200 and $300{ }^{\circ} \mathrm{C}$ can be explained by the antiferromagneticparamagnetic transition of NiO. As it is shown in the figure, in the whole temperature range the CTE of NiO/BZCY-SU is higher than that of the pure BZCY-EL perovskite material, which is in a good agreement with existing literature values. ${ }^{31}$ The difference is around 20 to $25 \%$, which is a comparably large value. For the final bi-layer assembly made of BZCY-EL and NiO/BZCY-SU this result might means that an optimisation of the co-sintering process will be required to match these properties. Slow heating rates will play a beneficial role in levelling the creep stress. During the cooling step, such difference in CTE might result in compressive stress in the electrolyte layer, which is most probably tolerable.
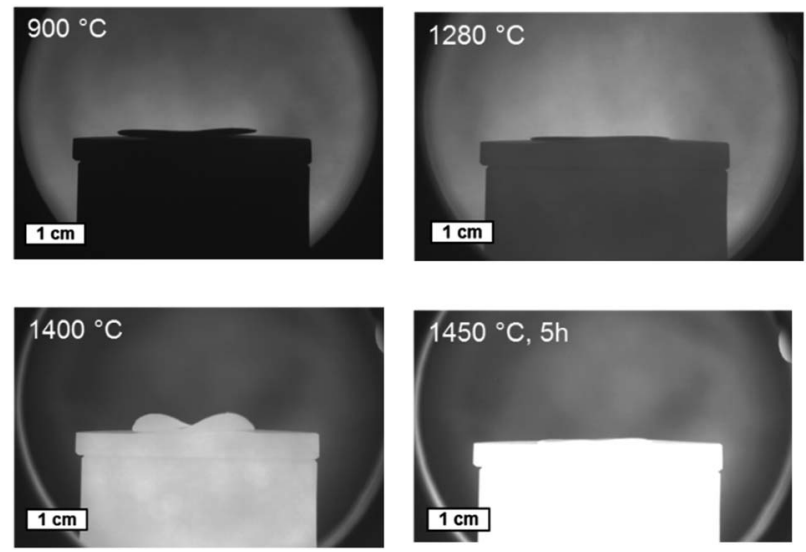

Fig. 7 Sintering behaviour of a bi-layer assembly of BZCY-NiO/BZCY at different temperatures captured in an optical dilatometer. 
a)

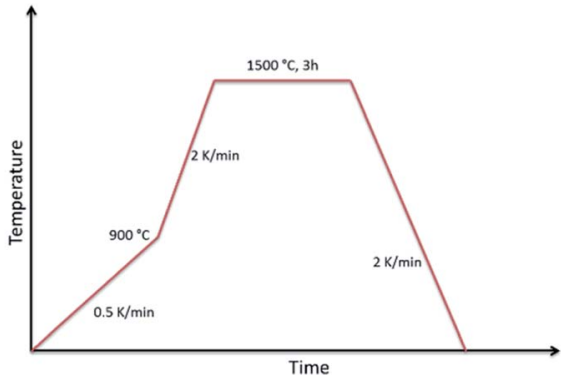

3.4.4. Sintering studies on bi-layer assemblies and upscaling. The protonic ceramic half cells in the present study consist of a BZCY-EL electrolyte and a NiO/BZCY-SU substrate, fabricated by sequential tape-casting, substrate lamination and co-firing. During the co-firing two important properties need to be ensured: gas tightness of the electrolyte layer and flatness of the bi-layer assembly. The latter is influenced by the sintering behaviour of the single materials and the sintering parameters. The bending behaviour of a bi-layer assembly during the heat treatment was monitored with the optical dilatometer. Selected images representing the assembly (electrolyte side heading upwards) at different temperatures are shown in Fig. 7. The disk sample changes its shape during the heat treatment and becomes flat only after $5 \mathrm{~h}$ holding time at $1450{ }^{\circ} \mathrm{C}$. This observation indicates that even if the electrolyte layer is already dense at this temperature, certain holding time is necessary for the whole structure to relax and to achieve geometrical flatness.

Combining the knowledge collected about the sample behaviour as a function of the heat treatment, half-cells were processed and co-fired to increased area of about $25 \mathrm{~cm}^{2}$. Fig. $8 \mathrm{a}$ depicts the thermal program applied in the cell scale-up and Fig. $8 \mathrm{~b}$ shows an image of a sintered half-cell.

\subsection{Characterisation of sintered half-cells}

3.5.1. XRD analysis. XRD analysis was performed on the half-cells to control the phase composition after sintering. The results are depicted in Fig. 9, which shows a representative sample sintered at $1500{ }^{\circ} \mathrm{C}$ for $6 \mathrm{~h}$. On the substrate side only $\mathrm{NiO}$ and the BZCY main phases were detected. Quantitative analysis with the Rietveld refinement showed a $60: 40$ ratio of

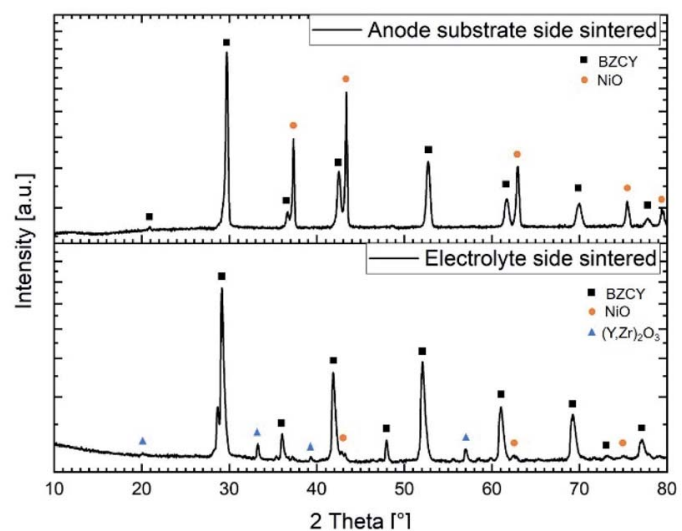

Fig. 9 X-ray diffraction patterns recorded on both sides of a half-cell sintered at $1500{ }^{\circ} \mathrm{C}$ for $6 \mathrm{~h}$.

these two phases, respectively. Analysis of the electrolyte layer shows a quite larger amount of $\mathrm{NiO}$ (around $2 \mathrm{wt} \%$ ) compared to the nominally added $0.5 \mathrm{wt} \%$ to the starting raw powder mixture (Table 2). We assume that this higher content of Ni can be explained by the formation and dissociation of the $\mathrm{BaY}_{2} \mathrm{NiO}_{5}$ transient liquid phase. Since the X-ray penetration depth for this material is estimated to be around 5-10 $\mu \mathrm{m}$, and the electrolyte thickness is larger than this, it is certain that the substrate layer composition does not affect this observation. The formation of Ni-rich areas in the electrolyte can potentially be the origin of cracks and electronic leakage.NiO to Ni reduction (during operation) is usually associated with a volume change and it could also lead to short circuits when Ni particles become interconnected throughout the electrolyte layer. However, in the present case there are no indications of crack formation or other undesired effects regarding to the integrity of the final electrolyte layer. Furthermore, based on the XRD analysis, a considerable amount (about $9 \mathrm{wt} \%$ ) of a secondary phase with the space group $I a \overline{3}$ and a lattice parameter of $a=$ 10.65(2) A was found. Pristine $\mathrm{Y}_{2} \mathrm{O}_{3}$ has a slightly lower lattice parameter of $a=10.60 \AA$, thus suggesting most probably formation of a $\mathrm{Y}$ rich phase with some additions of $\mathrm{Zr}$ and Ce. This assumption is supported by the EDX measurements in the following Section 3.5.2, where also the formation of the Ycontaining phase will be discussed in more detail. BZCY phase in the electrolyte and in the substrate shows some variation considering the lattice parameter (Table 4). This observation can be associated with the difference in composition as listed in Table 2 but also with the slight Ni excess provided by the support layer.

Fig. 10 depicts the X-ray diffraction patters recorded on both sides of a sintered half-cell after reduction in $\mathrm{H}_{2} / \mathrm{Ar}$. Both in the substrate and in the electrolyte layer $\mathrm{Ni}$ metallic and $\mathrm{Y}$ rich oxide phase were detected besides the BZCY main perovskite phase.

Literature data for Ni-free BZC20Y17.5 sintered by SPS and annealed at $1500{ }^{\circ} \mathrm{C}$ shows a lattice parameter $a=4.280 \AA^{32}$ Ceramic BZC20Y17.5 with 0.5 wt\% NiO and $a=4.263 \AA$ is roughly comparable to the lattice parameter of BZCY-EL 
Table 4 Lattice parameters of the different phases in electrolyte and substrate layers

\begin{tabular}{lll}
\hline Phase & Lattice parameter $[\AA]$ & Comment \\
\hline BZCY-SU & $a=4.260(6)$ & Calcined at $1300{ }^{\circ} \mathrm{C}$ \\
BZCY-SU sintered & $a=4.256(3)$ & Sintering temperature $1500{ }^{\circ} \mathrm{C}$ for $6 \mathrm{~h}$ \\
BZCY-SU reduced & $a=4.256(4)$ & Reduced in $\mathrm{Ar} / \mathrm{H}_{2}$ at $900{ }^{\circ} \mathrm{C}$ for $5 \mathrm{~h}$ \\
BZCY-EL sintered & $a=4.270(6)$ & Sintering temperature $1500{ }^{\circ} \mathrm{C}$ for $6 \mathrm{~h}$ \\
BZCY-EL reduced & $a=4.251(1)$ & Reduced in $\mathrm{Ar} / \mathrm{H}_{2}$ at $900{ }^{\circ} \mathrm{C}$ for $5 \mathrm{~h}$ \\
YZrO-EL sintered & $a=10.65(2)$ & Sintering temperature $1500{ }^{\circ} \mathrm{C}$ for $6 \mathrm{~h}$
\end{tabular}

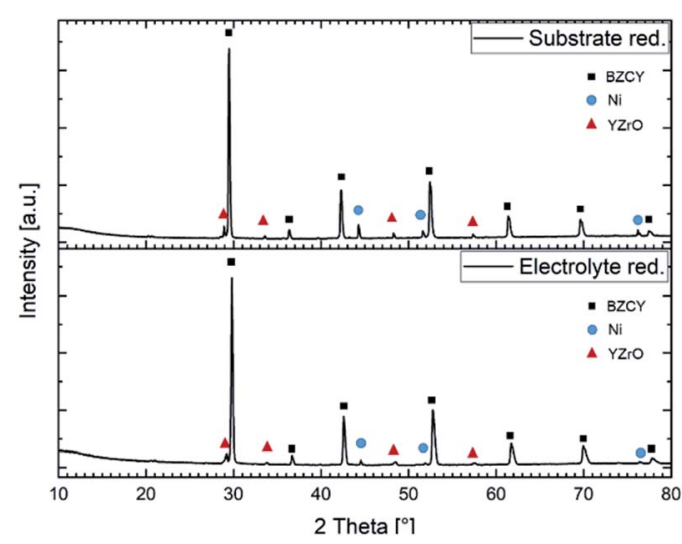

Fig. $10 \mathrm{X}$-ray diffractograms of a reduced anode substrate and a reduced electrolyte layer sintered at $1500{ }^{\circ} \mathrm{C}$ for $6 \mathrm{~h}$.

obtained in this work. ${ }^{32}$ It is typical for SSRS samples that they have a smaller lattice parameter than Ni-free samples, see discussion in ref. 24 , the more $\mathrm{Ni}$ the lower the lattice parameter. This also fits to the BZCY-SU having a smaller lattice parameter than BZCY-EL because the anode has huge NiOexcess. It is typically observed that samples treated below about $1400^{\circ} \mathrm{C}$ have a too small lattice parameter (BZCY-SU 4.26 instead of expected $4.28 \AA$ ), see e.g. also $^{33}$ for BZY. It probably means that not all $\mathrm{Y}$ is properly incorporated as dopant on the $\mathrm{B}$ site (even if no secondary phase containing the remaining $\mathrm{Y}$ is visible).

3.5.2. Microstructure. To gain more information about the microstructure and phases formed during the sintering and reduction, SEM analysis of the layer systems were performed. SEM images were taken from cross sections in "as sintered" state and after reduction of $\mathrm{NiO}$ to Ni. Fig. 11 shows representative specimens in both states. The electrolyte layer thickness could be adjusted by the variation of the tape-casting parameters. The layer combination in Fig. 11a was fabricated with the standard parameters described in Section 3.2, which led to a final thickness of the electrolyte of about $20 \mu \mathrm{m}$. The assintered anode substrate shows a homogeneous distribution of BZCY and NiO. The specimen in Fig. 11b was fabricated using optimised parameters, including a blade gap of $50 \mu \mathrm{m}$, to decrease the electrolyte thickness as much as possible (around $10 \mu \mathrm{m}$ in final sintered state), which shows clearly the potential of the fabrication method. The substrate porosity in reduced state is around $30 \%$, which is sufficient for the gas transport to the electrolyte, since no water is formed at the anode side in PCFC.

Detailed microstructural analysis of the electrolyte layer, including elemental mapping, was performed for reduced sintered specimen $\left(1500^{\circ} \mathrm{C} / 6 \mathrm{~h}\right)$, as shown in Fig. 12 . The electrolyte layer has a constant thickness of around $10 \mu \mathrm{m}$, also over an extended lateral range (Fig. 12a). The cross-section SEM images also show some residual closed porosity in this layer. Furthermore, a secondary phase was found (medium grey grains in Fig. 12b). EDX line scans in (Fig. 12c and d) were performed as indicated with the two red arrows in Fig. 12b. The EDX line scans in Fig. 12d clearly show that the secondary phase (gray feature in the middle of line scan 2) is Y rich, while Ba and Ce are depleted. Since the EDX signal also covers parts of the

a)

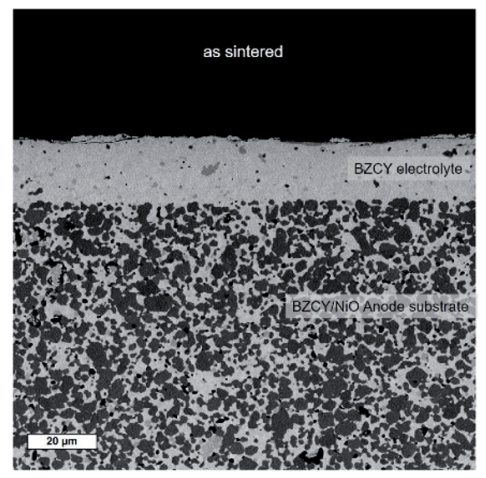

b)

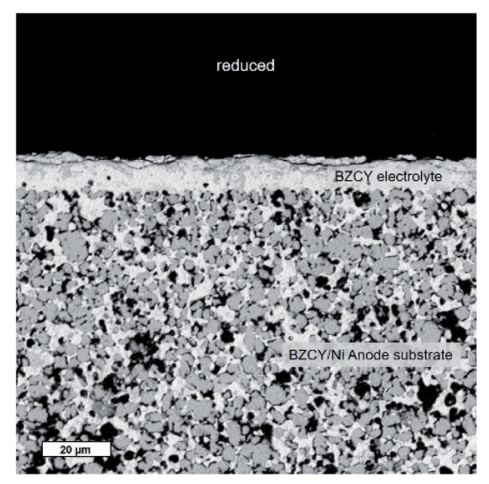

Fig. 11 SEM cross sections of final sintered BZCY-NiO/BZCY bi-layer assemblies at $1500{ }^{\circ} \mathrm{C}$ for $6 \mathrm{~h}$. (a) Unreduced, (b) reduced in $\mathrm{Ar} / \mathrm{H}_{2}$ at $900{ }^{\circ} \mathrm{C}$. 
a)

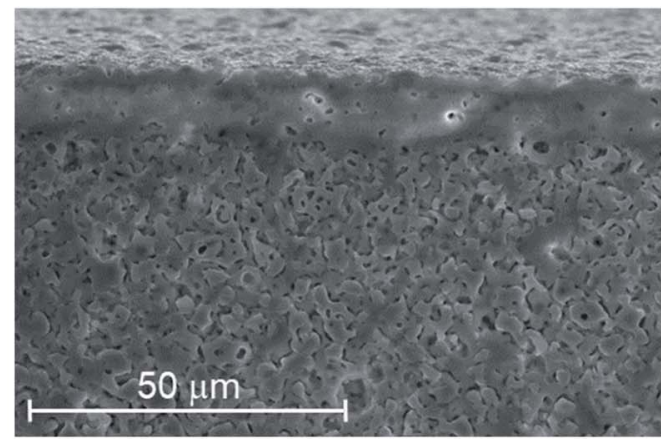

c)

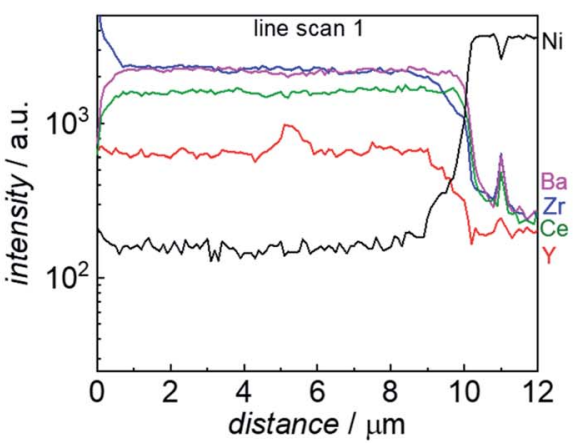

b)

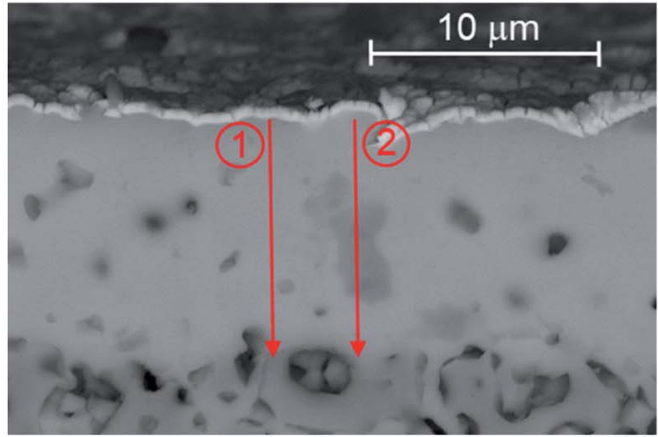

d)

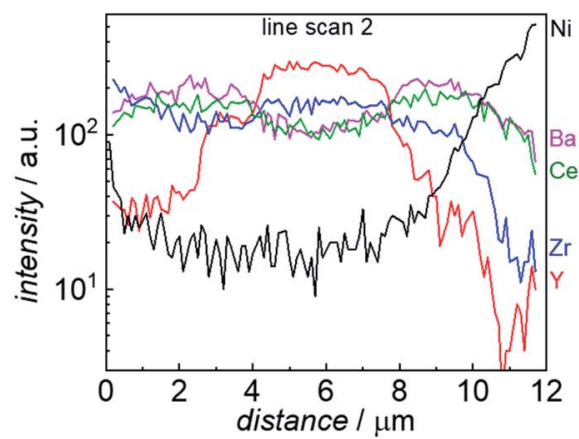

Fig. 12 (a) and (b) SEM image of FIB cross section of a reduced sample (sintered $6 \mathrm{~h}$ at $1500^{\circ} \mathrm{C}$, reduced at $800{ }^{\circ} \mathrm{C}$ ). (c) and (d) EDX line profiles measured along the red arrows.

surrounding material, it is not completely clear if it is pure $\mathrm{Y}_{2} \mathrm{O}_{3}$ or a $\mathrm{Y}, \mathrm{Zr}$ mixed oxide. As indicated by the XRD analysis in Fig. 10, there is an oxide secondary phase formed with slightly larger lattice parameter than $\mathrm{Y}_{2} \mathrm{O}_{3}$, which is in line with the observed by SEM Y-rich mixed oxide areas.

For specimens sintered at $1550{ }^{\circ} \mathrm{C}$, SEM images of FIB cross sections show the absence of pores in the BZCY layer. The higher sintering temperature also promotes strongly increased amount of the $\mathrm{Y}_{2} \mathrm{O}_{3}$ secondary phase with grains that occasionally penetrate the whole electrolyte layer. This $\mathrm{Y}_{2} \mathrm{O}_{3}$ formation is detrimental as in humid conditions it may transform to $\mathrm{Y}(\mathrm{OH})_{3}$, and also because the amount of $\mathrm{Y}$ segregated into this secondary phase is missing in the BZCY, which will decrease the proton uptake. $1550{ }^{\circ} \mathrm{C}$ is a suitable sintering temperature for ceramic samples of identical cation composition, ${ }^{34}$ but apparently it is too high for a BZCY electrolyte layer (which is inevitably more susceptible to $\mathrm{BaO}$ loss), and in combination with an extremely Ni-rich anode layer as support (which might modify the transient liquid phase formation).

3.5.3. Discussion of the sintering process. An extended range of sintering conditions was tested for small size electrolyte-substrate assemblies to obtain a more detailed understanding of the complex sintering process. The heating rates are the same as in Fig. 8a, only temperatures and soaking time were varied. While all assemblies sintered at higher $T$ show a dark grey colour, samples sintered at $1400-1430{ }^{\circ} \mathrm{C}$ have a lighter, slightly brownish colour, potentially indicating incomplete densification ( $c f$. shrinkage curve in Fig. 5). For some samples open sintering, sintering covered by a MgO crucible, and under a $\mathrm{MgO}$ crucible with some $\mathrm{BaZrO}_{3} / 20$ wt $\% \mathrm{BaCO}_{3}$ powder mixture placed close by were compared, to explore if $\mathrm{BaO}$ loss via the gas phase is an issue. However, no significant difference was found either in optical and SEM images or XRD. This can be interpreted such that the BZCY/NiO anode composite is potentially a much stronger sink for $\mathrm{BaO}$ than the gas phase, and the formation of large amounts of $\mathrm{Y}_{2} \mathrm{O}_{3}$ at high $T$ and/or long time can be attributed to this effect (see discussion below).

The top-view optical and SEM images of the electrolyte side are collected in Fig. 13. The optical images for samples sintered at $\leq 1500{ }^{\circ} \mathrm{C}$ show small dark features. They represent dips rather than extra particles on top of a smooth surface; their concentration decreases with increasing $T$ but is hardly affected by the soaking time. At $1520^{\circ} \mathrm{C}$ and above, large structures with irregular shape and rounded edge appear, with increasing concentration at higher $T$ and/or longer soaking time. The SEM images confirm these trends. They show that the grain size increases from $\approx 1 \mu \mathrm{m}$ at $1450{ }^{\circ} \mathrm{C}$ to $\approx 3 \mu \mathrm{m}$ at $1550^{\circ} \mathrm{C}$, while an increase of soaking time from $1 \mathrm{~h}$ to $6 \mathrm{~h}$ has less influence. For selected samples, EDX measurements were performed, they indicate that the large particles appearing at high sintering temperatures are high in $\mathrm{Y}$ and $\mathrm{O}$. For samples sintered for $1 \mathrm{~h}$ at $T \leq 1480^{\circ} \mathrm{C}$, occasionally particles with strongly increased $\mathrm{Ni}$, $\mathrm{Y}$ content and some $\mathrm{Ba}$ are observed, which can tentatively be assigned to a $\mathrm{BaY}_{2} \mathrm{NiO}_{5}$-related phase.

The XRD results are presented in Fig. 14, which shows pronounced differences with time and temperature. For a soaking time of $1 \mathrm{~h}$, the lattice parameter moderately increases with sintering temperature (Fig. 14a). This is in line 

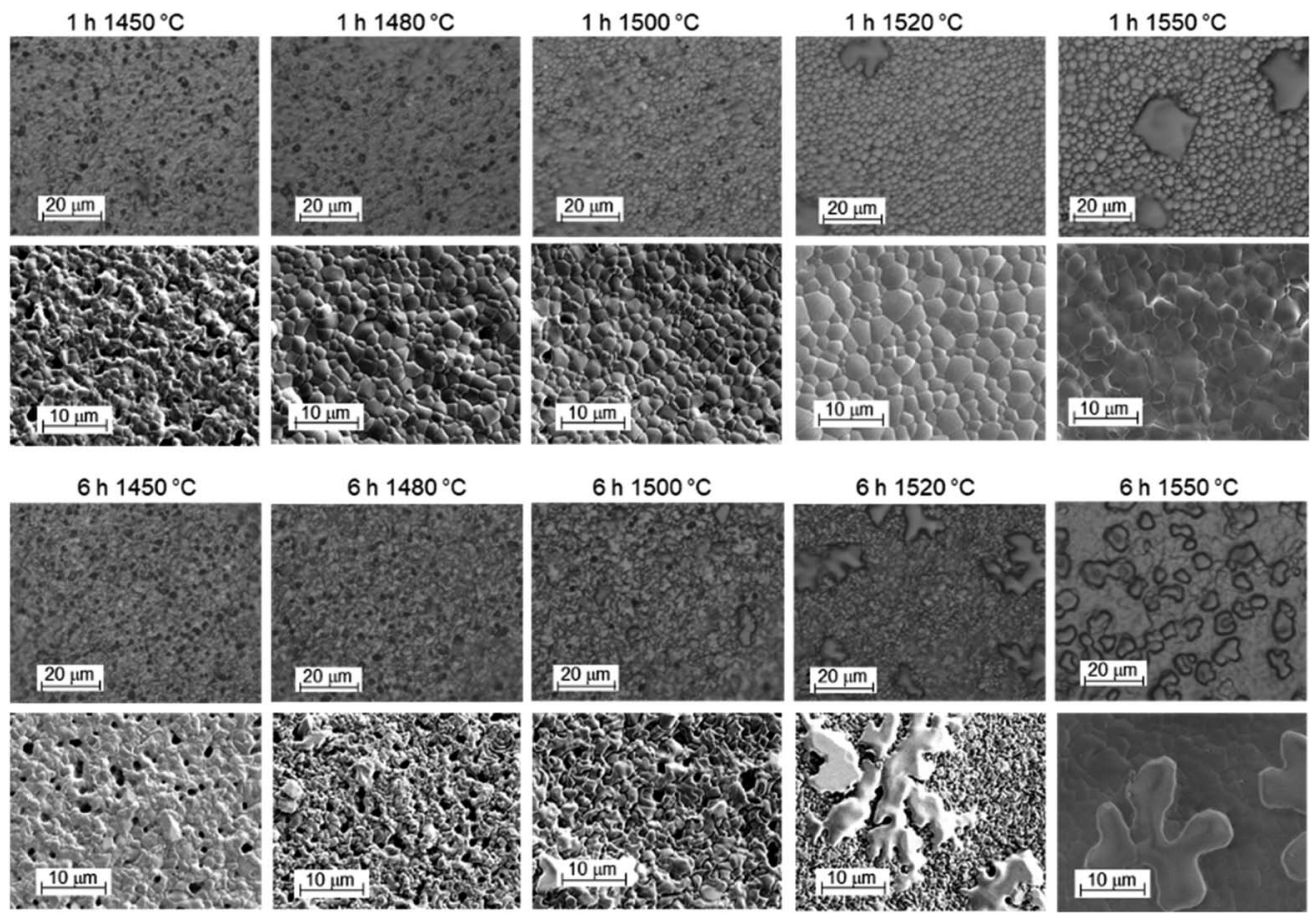

Fig. 13 Top-view optical microscopy and SEM images of the electrolyte side of BZCY assemblies after sintering for $1 \mathrm{~h}$ (top row) or $6 \mathrm{~h}$ (bottom row) at different temperatures.

with literature reports, which indicate that an elevated temperature is required for full $\mathrm{Y}$ incorporation on the B site of $\mathrm{BaZrO}_{3}{ }^{33} \mathrm{In}$ contrast, the lattice parameter of samples with $6 \mathrm{~h}$ soaking time decreases with increasing $T$. This goes in parallel with a strongly increasing $\mathrm{Y}_{2} \mathrm{O}_{3}$ fraction (Fig. 14b and c; exemplary diffractogram in Fig. 14e) and the observation of large
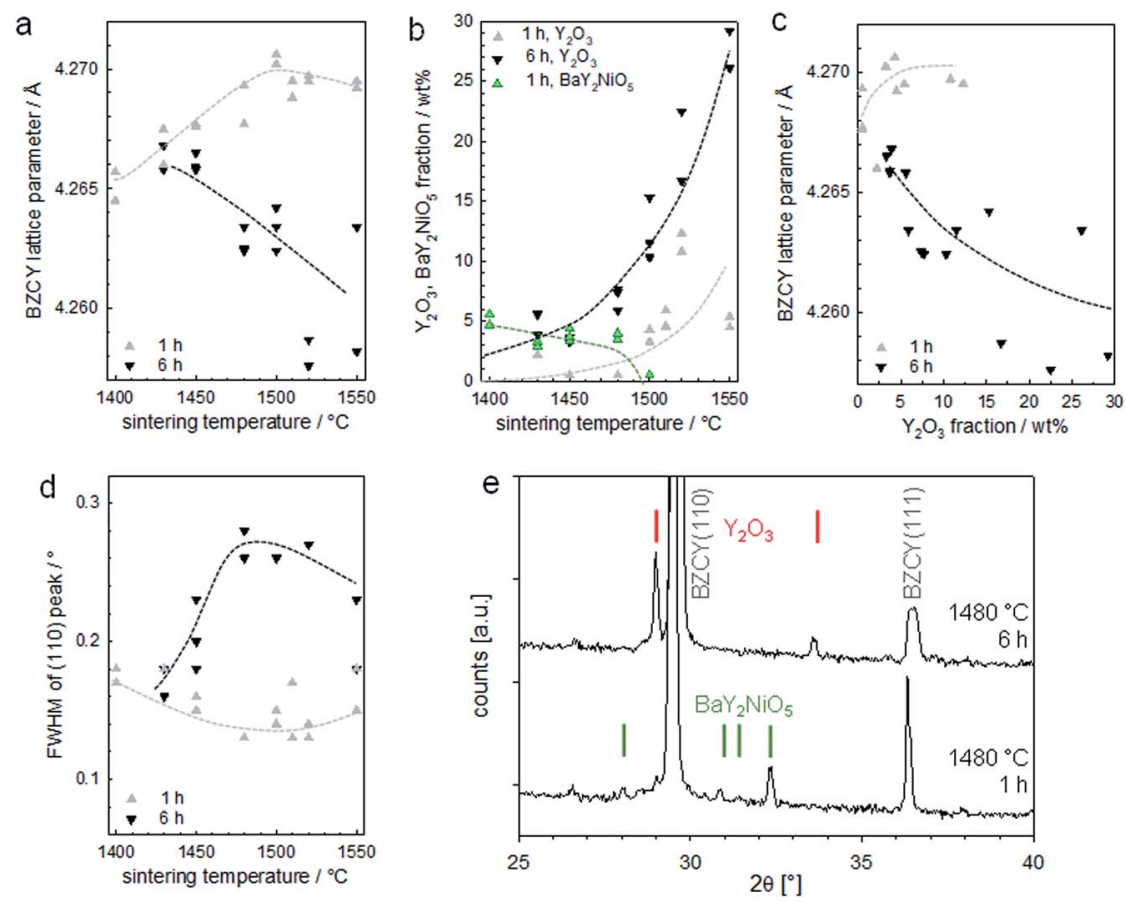

Fig. $14 \mathrm{XRD}$ results for the assemblies of Fig. 13. (a) Lattice parameter of the $\mathrm{BZCY}$ perovskite, (b) fraction of $\mathrm{Y}_{2} \mathrm{O}_{3}$ and $\mathrm{BaY}_{2} \mathrm{NiO}_{5}$ second phases, (c) relation of BZCY lattice parameter and $\mathrm{Y}_{2} \mathrm{O}_{3}$ fraction, (d) full width at half maximum of the (110) peak of the BZCY, (e) diffractograms for samples sintered for $1 \mathrm{~h}$ and $6 \mathrm{~h}$ at $1480{ }^{\circ} \mathrm{C}$ with $\mathrm{Y}_{2} \mathrm{O}_{3}$ and $\mathrm{BaY}_{2} \mathrm{NiO}_{5}$ peaks indicated. 
$\mathrm{Y}_{2} \mathrm{O}_{3}$ grains in optical and SEM images. The precipitation of $\mathrm{Y}_{2} \mathrm{O}_{3}$ as second phase is a typical phenomenon when $\mathrm{Ba}(\mathrm{Zr}, \mathrm{Y}) \mathrm{O}_{3}$ perovskites suffer from $\mathrm{BaO}$ loss, as this can restore the balance of A- and B-site cations and avoid the presence of energetically unfavourable cation vacancies.

It is important to note that the $\mathrm{BaO}$ sink that is acting here is not evaporation into the gas phase, as one might initially guess based on the large surface to volume ratio of the BZCY layers. Samples sintered under a $\mathrm{MgO}$ cover, or under a cover with $\mathrm{BaZrO}_{3} / \mathrm{BaCO}_{3}$ powder placed nearby to decrease potential $\mathrm{BaO}$ loss via the gas phase do not show systematic differences in the appearance of secondary phases in optical/SEM images or XRD. Thus, the $\mathrm{BaO}$ sink is the formation of $(\mathrm{Ba}, \mathrm{Ni}, \mathrm{Y}) \mathrm{O}_{x}$ transient liquid phases, which extracts $\mathrm{Ba}$ from the perovskite. ${ }^{24}$ The fact that the anode layer is very NiO-rich makes it a very effective $\mathrm{BaO}$ sink. The large size of the $\mathrm{Y}_{2} \mathrm{O}_{3}$ grains and their peculiar shape strongly suggests they were formed by passing through a liquid state. Since the melting point of pure $\mathrm{Y}_{2} \mathrm{O}_{3}$ is above $2400{ }^{\circ} \mathrm{C}$, these particles are probably remainders of a $(\mathrm{Ba}, \mathrm{Ni}, \mathrm{Y})$ $\mathrm{O}_{x}$ transient liquid phase. Their growing concentration with soaking time indicates there is a strong interaction of the $10 \mu \mathrm{m}$ thin electrolyte layer with the much thicker NiO-rich anode support (the small $0.5 \mathrm{wt} \% \mathrm{NiO}$ addition in the electrolyte layer is too low to form such large amounts of $(\mathrm{Ba}, \mathrm{Ni}, \mathrm{Y}) \mathrm{O}_{x}$ transient liquid phase). The liquid phase formation in the anode layer appears to increase with temperature (samples sintered at $1550{ }^{\circ} \mathrm{C}$ have a high tendency to stick to the setter plate), and correspondingly also the $\mathrm{BaO}$ extraction from the electrolyte layer becomes larger. Such detrimental interactions are expected even if no $\mathrm{NiO}$ is added into the electrolyte layer.

XRD for samples with $1 \mathrm{~h}$ soaking time show small but wellperceptible peaks of $\mathrm{BaY}_{2} \mathrm{NiO}_{5}$ at $T \leq 1480{ }^{\circ} \mathrm{C}$ (green symbols in Fig. 14b, diffractogram shown in Fig. 14e), in line with the observation of some Ni,Y,Ba-rich particles by SEM-EDX. The $\mathrm{BaY}_{2} \mathrm{NiO}_{5}$ peaks vanish for longer soaking time, which emphasizes the transient character of the low-melting $\mathrm{BaY}_{2} \mathrm{NiO}_{5}$ phase.

For samples with $1 \mathrm{~h}$ soaking time, the XRD peak width decreases slightly with increasing $T$, while for the $6 \mathrm{~h}$ samples an increase (with some downturn at highest $T$ ) is observed in Fig. $14 \mathrm{~d}$ and e. Since the grain sizes are well above the range which causes size broadening, this broadening is tentatively attributed to the formation of intergranular Ba and/or $\mathrm{Y}$ concentration gradients.

We can summarize that from the viewpoints of electrolyte layer morphology, BZCY lattice parameter, and concentration of second phases, long soaking times and temperatures above $1500{ }^{\circ} \mathrm{C}$ are not beneficial. The sintering involving a transient liquid phase in the NiO-rich anode as well as in the NiO-poor BZCY electrolyte layer is a complex process, but with appropriately chosen conditions dense anode-electrolyte assemblies with minimized secondary phase content can be achieved.

\subsection{Electrical properties}

Fig. 15 shows exemplary conductivity measurements of electrolyte-support assembly samples sintered at $1450{ }^{\circ} \mathrm{C}$ and a)

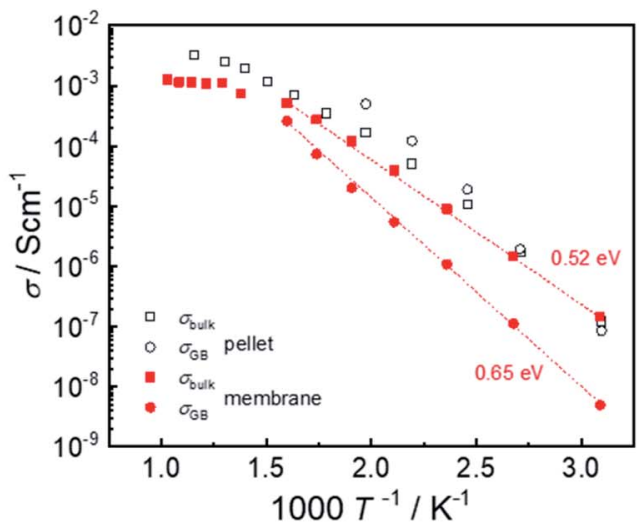

b)



Fig. 15 Arrhenius plot of reduced assemblies sintered (a) $6 \mathrm{~h}$ at $1450{ }^{\circ} \mathrm{C}$, (b) $3 \mathrm{~h}$ at $1500{ }^{\circ} \mathrm{C}$. For comparison the values of a ceramic pellet sample are shown (nominally identical cation composition and $\mathrm{NiO}$ addition, sintered $4 \mathrm{~h}$ at $1550{ }^{\circ} \mathrm{C}$ ). Assemblies were measured in wet $\mathrm{H}_{2}\left(\mathrm{pH}_{2} \mathrm{O}=20 \mathrm{mbar}\right)$, the pellet in wet $\mathrm{N}_{2}$ from $700^{\circ} \mathrm{C}$ to $400^{\circ} \mathrm{C}$ and wet $2 \% \mathrm{H}_{2}$ at lower $T$.

$1500{ }^{\circ} \mathrm{C}$. Under these conditions (wet $\mathrm{N}_{2}$ or wet diluted $\mathrm{H}_{2}$ ) the proton conductivity dominates. ${ }^{2}$ In addition to the highfrequency arc that is assigned to bulk conductivity, the impedance spectra of electrolyte as well as pellet samples exhibit an additional semicircle which is related to the well-known blocking character of the grain boundaries in $\mathrm{Ba}(\mathrm{Zr}, \mathrm{Ce}, \mathrm{Y}) \mathrm{O}_{3-z}$ materials ${ }^{2,35-37}$ and which typically exhibits a larger activation energy than the bulk proton conductivity. At temperature above $\approx 300{ }^{\circ} \mathrm{C}$ bulk and GB arcs cannot be resolved any more, and only the total conductivity is given. For comparison, also the bulk and GB conductivity of a ceramic pellet with same Ce, Y and Ni content is shown. The bulk conductivity of the electrolytes is very similar to that of the ceramic pellet; its activation energy of $0.52 \mathrm{eV}$ (determined from a plot of $\log (\sigma T) v s .1 / T$ ) agrees well with literature data for $\mathrm{BaZr}_{0.6} \mathrm{Ce}_{0.2} \mathrm{Y}_{0.2} \mathrm{O}_{3-\delta}-2 \mathrm{wt} \%$ $\mathrm{NiO}^{38}$ On the other hand, the GB conductivity of the electrolyte in the assembly samples is about one order of magnitude lower than that of the ceramic pellet. The corresponding decrease of the total conductivity is more severe at low $T$ and increasingly vanishes above $400{ }^{\circ} \mathrm{C}$. The difference in GB conductivity may be related to a smaller grain size in the membrane samples ( $c f$. higher sintering $T$ for ceramic pellet), but also to detrimental 
effects of $\mathrm{BaO}$ evaporation at the exposed film surface, and potential Ni-indiffusion from the supporting anode layer (Fig. 12c and d).

In general it is found that $\mathrm{NiO}$ addition to $\mathrm{Ba}(\mathrm{Zr}, \mathrm{Ce}, \mathrm{Y}) \mathrm{O}_{3-\delta}$ is beneficial for sintering properties and grain growth but decreases the bulk proton conductivity, see e.g. ${ }^{39-41}$ This is at least in part due to a decreased proton incorporation. ${ }^{\mathbf{2 4 , 2 5 , 3 8}}$ Even if $\mathrm{NiO}$ is not deliberately added into the $\mathrm{Ba}(\mathrm{Zr}, \mathrm{Ce}, \mathrm{Y}) \mathrm{O}_{3-\delta}$ layer of co-sintered anode-supported cells, its presence in the anode layer affects the $\mathrm{Ba}(\mathrm{Zr}, \mathrm{Ce}, \mathrm{Y}) \mathrm{O}_{3-\delta}$ electrolyte layer. Thus, it is not surprising that the electrolyte conductivity extracted from such cells are lower than expected for ceramic pellets sintered without NiO addition (data compilation e.g. in ref. 25 and 40). This observation applies for different methods of electrolyte layer preparation such as co-pressing, dip coating, screen printing etc. At $600{ }^{\circ} \mathrm{C}$ the present membrane sintered at $1500{ }^{\circ} \mathrm{C}$ reaches a total conductivity of about $0.003 \mathrm{~S} \mathrm{~cm}^{-1}$ which is comparable to the literature data. The present approach of anode and electrolyte sequential tape-casting and co-sintering has the advantage that it is suitable for further upscaling of the cell area, in contrast to methods based on pressing/co-pressing.

\section{Conclusions}

In this work it was shown that protonic ceramic half-cells can be successfully manufactured by using the scalable and industrially established tape-casting process, applying solid state reactive sintering. BZCY perovskite powder for the substrate layer was synthesized via a solid-state reaction route, while the powder for the electrolyte layer still contains some unreacted $\mathrm{BaCO}_{3}$. The powder properties were adjusted for the tapecasting process by controlling the calcination temperatures which were $1100{ }^{\circ} \mathrm{C}$ and $1300{ }^{\circ} \mathrm{C}$ for electrolyte and substrate, respectively. The electrolyte layer thickness was between 10 and $20 \mu \mathrm{m}$, while anode substrate layers consisting of a BZCY-NiO composite were around $250 \mu \mathrm{m}$ thick. To further increase the substrate layer thickness effectively, lamination technique was introduced, where heat and pressure were used to connect several tape-cast layers to each other.

The heat treatment of the green samples was studied by different methods to develop an optimised temperature profile. Therefore, the burn out of the organic additives was investigated by thermogravimetry. The sintering behaviour and the thermal expansion of the single layers was studied before the final sintering profile was adapted to the bi-layer combination of dense BZCY electrolyte and composite BZCY/NiO substrate. Sintering temperature of $1500{ }^{\circ} \mathrm{C}$ was found to be optimal. Extended soaking times are detrimental since they cause $\mathrm{BaO}$ loss from the electrolyte into the BZCY-NiO anode layer. A scaleup approach to a cell size of $25 \mathrm{~cm}^{2}$ was successful.

Sintered anode-electrolyte assemblies were characterized in detail by XRD and SEM. It was shown that the $\mathrm{BaY}_{2} \mathrm{NiO}_{5}$ transient liquid phase causes some inhomogeneities in the thin electrolyte layer by forming Y-rich domains after the decomposition of the phase itself. Nevertheless, the electrical properties are competitive compared to other data from literature.
The proton conductivity of the tape-cast half-cells was measured to be $\sigma=0.003 \mathrm{~S} \mathrm{~cm}^{-1}$ at $600{ }^{\circ} \mathrm{C}$ in humid atmosphere.

\section{Conflicts of interest}

There are no conflicts to declare.

\section{Acknowledgements}

This work was conducted thanks to the financial support of Federal Ministry of Education and Research BMBF, Germany under the funding reference 03SF0537A, C (ProtOMem Project). J. Deuschle, A. Fuchs, H. Hoier (MPI FKF Stuttgart) and Y.-J. Sohn (IEK-1, Forschungszentrum Jülich $\mathrm{GmbH}$ ) are highly acknowledged for performing the SEM, EDX and XRD studies.

\section{References}

1 K.-D. Kreuer, Solid State Ionics, 1999, 125, 285-302.

2 K. D. Kreuer, Annu. Rev. Mater. Res., 2003, 33, 333-359.

3 Y. Matsuzaki, Y. Tachikawa, T. Somekawa, T. Hatae, H. Matsumoto, S. Taniguchi and K. Sasaki, Sci. Rep., 2015, 5, 12640.

4 S. Hossain, A. M. Abdalla, S. N. B. Jamain, J. H. Zaini and A. K. Azad, Renewable Sustainable Energy Rev., 2017, 79, 750-764.

5 K. Leonard, W. Deibert, M. E. Ivanova, W. A. Meulenberg, T. Ishihara and H. Matsumoto, Membranes, 2020, 10, 339.

6 C. C. Duan, R. J. Kee, H. Y. Zhu, C. Karakaya, Y. C. Chen, S. Ricote, A. Jarry, E. J. Crumlin, D. Hook, R. Braun, N. P. Sullivan and R. O'Hayre, Nature, 2018, 557, 217-222.

7 S. Choi, C. J. Kucharczyk, Y. Liang, X. Zhang, I. Takeuchi, H.-I. Ji and S. M. Haile, Nat. Energy, 2018, 3, 202-210.

8 H. An, H.-W. Lee, B.-K. Kim, J.-W. Son, K. J. Yoon, H. Kim, D. Shin, H.-I. Ji and J.-H. Lee, Nat. Energy, 2018, 3, 870-875.

9 K. Bae, D. Y. Jang, H. J. Choi, D. Kim, J. Hong, B. K. Kim, J. H. Lee, J. W. Son and J. H. Shim, Nat. Commun., 2017, 8, 14553.

10 C. Duan, J. Tong, M. Shang, S. Nikodemski, M. Sanders, S. Ricote, A. Almansoori and R. O'Hayre, Science, 2015, 349, 1321-1326.

11 J. H. Tong, D. Clark, L. Bernau, A. Subramaniyan and R. O'Hayre, Solid State Ionics, 2010, 181, 1486-1498.

12 J. H. Tong, D. Clark, L. Bernau, M. Sanders and R. O'Hayre, J. Mater. Chem., 2010, 20, 6333-6341.

13 H. L. Dai, E. H. Da'as, S. P. Shafi, H. Q. Wang and L. Bi, J. Eur. Ceram. Soc., 2018, 38, 2903-2908.

14 L. S. Mahmud, A. Muchtar and M. R. Somalu, Renewable Sustainable Energy Rev., 2017, 72, 105-116.

15 J. Dailly, M. Marrony, G. Taillades, M. Taillades-Jacquin, A. Grimaud, F. Mauvy, E. Louradour and J. Salmi, J. Power Sources, 2014, 255, 302-307.

16 M. Marrony, M. Ancelin, G. Lefevre and J. Dailly, Solid State Ionics, 2015, 275, 97-100.

17 J. Dailly, G. Taillades, M. Ancelin, P. Pers and M. Marrony, J. Power Sources, 2017, 361, 221-226. 
18 J. Xiao, H. Yuan, L. Chen, C. Xiong, J. Ma, Y. Zhao, J. Chai, W. Du and X. Zhu, Int. J. Mod. Phys. B, 2017, 31, 1744062.

19 J. Huang, Y. Ma, M. Cheng and S. Ruan, Int. J. Hydrogen Energy, 2018, 43, 12835-12846.

20 S. H. Nien, C. S. Hsu, C. L. Chang and B. H. Hwang, Fuel Cells, 2011, 11, 178-183.

21 N. Sata, F. Han, H. Zheng, A. M. Dayaghi, T. Norby, M. Stange, R. Semerad and R. Costa, ECS Trans., 2021, 103, 1779-1789.

22 K. H. Ryu and S. M. Haile, Solid State Ionics, 1999, 125, 355367.

23 W. Deibert, M. E. Ivanova, W. A. Meulenberg, R. Vaßen and O. Guillon, J. Membr. Sci., 2015, 492, 439-451.

24 Y. Huang, R. Merkle and J. Maier, Solid State Ionics, 2020, 347, 115256.

25 D. Han, S. Uemura, C. Hiraiwa, M. Majima and T. Uda, ChemSusChem, 2018, 11, 4102-4113.

26 E. Kim, Y. Yamazaki, S. M. Haile and H. I. Yoo, Solid State Ionics, 2015, 275, 23-28.

27 D. Han, K. Shinoda, S. Tsukimoto, H. Takeuchi, C. Hiraiwa, M. Majima and T. Uda, J. Mater. Chem. A, 2014, 2, 1255212560.

28 K. Xie, R. Yan, Y. Jiang, X. Liu and G. Meng, J. Membr. Sci., 2008, 325, 6-10.

29 J. A. Lewis, Annu. Rev. Mater. Sci., 1997, 27, 147-173.
30 A. Kaiser, A. S. Prasad, S. P. Foghmoes, S. Ramousse, N. Bonanos and V. Esposito, J. Eur. Ceram. Soc., 2013, 33, 549-556.

31 A. Løken, S. Ricote and S. Wachowski, Crystals, 2018, 8, 365. 32 Y. Huang, PhD thesis, University of Stuttgart, 2020.

33 C. Hiraiwa, D. Han, A. Kuramitsu, A. Kuwabara, H. Takeuchi, M. Majima, T. Uda and R. Koc, J. Am. Ceram. Soc., 2013, 96, 879-884.

34 Y. Huang, R. Merkle and J. Maier, J. Mater. Chem. A, 2021, 9, 14775-14785.

35 M. Shirpour, B. Rahmati, W. Sigle, P. A. van Aken, R. Merkle and J. Maier, J. Phys. Chem. C, 2012, 116, 2453-2461.

36 F. Iguchi, C.-T. Chen, H. Yugami and S. Kim, J. Mater. Chem., 2011, 21, 16517-16523.

37 C. Kjølseth, H. Fjeld, Ø. Prytz, P. I. Dahl, C. Estournès, R. Haugsrud and T. Norby, Solid State Ionics, 2010, 181, 268-275.

38 D. Han, K. Goto, M. Majima and T. Uda, ChemSusChem, 2021, 14, 614-623.

39 N. Nasani, D. Pukazhselvan, A. V. Kovalevsky, A. L. Shaula and D. P. Fagg, J. Power Sources, 2017, 339, 93-102.

40 D. Han, J. Iihara, S. Uemura, K. Kazumi, C. Hiraiwa, M. Majima and T. Uda, J. Mater. Chem. A, 2016, 4, 1060110608.

41 S. Ricote, N. Bonanos, A. Manerbino, N. P. Sullivan and W. G. Coors, J. Mater. Chem. A, 2014, 2, 16107-16115. 